\title{
First report of genetic diversity and risk factor analysis of equine piroplasm infection in equids in Jilin, China
}

Shaowei Zhao ${ }^{\dagger}$, Hao Wang ${ }^{\dagger}$, Shuang Zhang ${ }^{\dagger}$, Suzhu Xie, Hang Li, Xuancheng Zhang and Lijun Jia*

\begin{abstract}
Background: Equine piroplasmosis (EP) is a tick-borne hemoprotozoan disease of equids, caused by Theileria equi and Babesia caballi. Equine piroplasmosis represents a serious challenge to the equine industry due to important economic losses worldwide. The present study aimed to evaluate the prevalence of Theileria equi and Babesia caballi infections in equids from Jilin Province, China.

Methods: A total of 220 blood samples (192 horses and 28 donkeys/mules) were collected from March 2018 to October 2019 in five districts of Jilin Province and analyzed by PCR. Potential risk factors, including the region, sex, management, and host species of the animals were assessed in relation to T. equi infection. Moreover, the V4 hypervariable region of the T. equi 185 rRNA gene was analyzed to identify specific genotypes.

Results: The overall prevalence of T. equi in equids was $27.7 \%$, whereas B. caballi infection was not identified. The district with the highest positive rate was Baicheng (43.3\%), followed by Tonghua (28.9\%), Yanbian (26.4\%), Jilin (23.3\%), and Liaoyuan (20.9\%). The sex of the animals and farm management were identified as main risk factors, which were significantly associated with the prevalence of Equine piroplasmosis $(P<0.05)$. The risk factor analysis indicated that the females were at a higher risk (OR: $2.48,95 \% \mathrm{Cl}: 1.17-5.27$ ) of being infected compared to the males, whereas the organized farm was protective factor (OR: $0.42,95 \% \mathrm{Cl}: 0.22-0.80$ ). The phylogenetic analyses revealed that there were two T. equi genotypes ( $\mathrm{A}$ and $\mathrm{E}$ ) in Jilin.
\end{abstract}

Conclusions: Our findings provided important epidemiological data for the prevention and control of T. equi infection in Jilin, China.

Keywords: Equine piroplasmosis, Theileria equi, Risk factors, Genetic diversity, Epidemiology

\section{Background}

Equine piroplasmosis (EP) is a tick-borne disease caused by the hemoprotozoan parasites, Theileria equi and Babesia caballi, which causes fever, hemolytic anemia, jaundice, inappetence, and hemoglobinuria in all equid species (horses, donkeys, mules and zebras) [1]. Both

\footnotetext{
*Correspondence: lijunjia1015@sohu.com

'Shaowei Zhao, Hao Wang and Shuang Zhang contributed equally to this work

Laboratory of Veterinary Microbiology, Department of Veterinary Medicine, Agriculture College of Yanbian University, No. 977 Park Road, Yanji 133000, China
}

hemoparasites are obligate intraerythrocytic protozoans classified within the phylum Apicomplexa, and are primarily transmitted by ixodid ticks belonging to the genera Dermacentor, Hyalomma and Rhipicephalus [2]. Equids infected with T. equi may represent long-term reservoirs, even if they have recovered from an acute or early infection. However, B. caballi causes a self-limiting infection that is naturally cleared by the horse's immune system after 12 to 42 months post-infection [3]. Moreover, horses infected with equine piroplasmosis are strictly restricted for trade and sport. The causal agents of EP 
have been reported for more than 100 years, and this disease is widely distributed throughout Central and South America, Africa, Asia, Middle East and southern Europe, where it causes a substantial economic impact to the equine industry [4].

According to the Food and Agriculture Organization (FAO) statistics, the breeding stock of donkeys and horses in China was ranked second and third in the world, respectively [5]. The horse industry is primarily distributed in areas of northeast, north, and northwest China. Recently, the horse industry has displayed a wide range of development, which is not limited to agricultural production, but also the tourism, entertainment, competition, and food industries. Equine piroplasmosis is considered to be a notifiable disease by the World Organization for Animal Health (OIE), which has been reported in many regions of China, with prevalence rates varying from $10.9-80.1 \%$ (Table 1 ). The prevalence of EP was significantly higher in regions, such as Ningxia 80.1\% [6], Guizhou 74.0\% [7], and Yunnan $73.8 \%$ [6]. In addition, Xinjiang, Shanxi, and Hebei were also considered endemic areas of EP, with a prevalence of $40.8 \%$ [8], 44.3\% and 54.7\% [6], respectively.

There are currently several diagnostic methods that can be used to diagnose infection with equine piroplasm, including thin smear examination, complement fixation test (CFT), immunofluorescent antibody test (IFAT), enzyme linked immunosorbent assay (ELISA), and polymerase chain reaction (PCR). The application of PCR assays, which target equine piroplasm genes, such as the EMA-1 gene, $B C-48$ gene, and $18 S$ ribosomal RNA (rRNA), have demonstrated higher analytical sensitivity and specificity than serological and microscopic detection $[9,10]$. Although EP is an endemic disease among equids in Jilin Province, there are few studies involving the molecular epidemiology and interspecific genetic diversity of equine piroplasm. Thus, the aim of the present study was to determine the prevalence of equine piroplasm in equids from Jilin province in the northeastern region of China. We also sought to determine the risk factors associated with the occurrence of infection and genotypes of equine piroplasm in this region.

\section{Methods}

\section{Study area and sample collection}

From March 2018 to October 2019, a total of 220 blood samples of equids were collected from the following five counties in Jilin Province (Fig. 1): Liaoyuan; Baicheng; Jilin; Yanbian; and Tonghua. Blood was aseptically collected from the jugular vein from each animal using K2-EDTA vacuum tubes (Solarbio, Beijing, China) and carefully stored at $-20^{\circ} \mathrm{C}$ until DNA extraction. A predesigned epidemiological questionnaire consisting of information regarding the region, sex, management, and host species of the animals was filled out with the help of farm owners to evaluate the risk factors associated with prevalence of equine piroplasm.

\section{DNA extraction and PCR amplification}

The genomic DNA was extracted from $200 \mu \mathrm{l}$ of each equine blood sample using a blood extraction kit (Vazyme, Nanjing, China) according to the manufacturer's recommendations, and was subsequently stored at $-20{ }^{\circ} \mathrm{C}$ until further use. The extracted DNA was used as

Table 1 Prevalence of equine piroplasmosis in each area of China

\begin{tabular}{|c|c|c|c|c|c|}
\hline \multirow[t]{2}{*}{ Region } & \multirow[t]{2}{*}{ Diagnostic method } & \multicolumn{3}{|l|}{ Positive rates (\%) } & \multirow[t]{2}{*}{ References } \\
\hline & & T. equi $(95 \%$ Cl) & B. caballi $(95 \% \mathrm{Cl})$ & Total $(95 \% \mathrm{Cl})$ & \\
\hline Xinjiang & PCR & $40.8(37.2-44.4)$ & na & $40.8(37.2-44.4)$ & {$[8]$} \\
\hline Yunnan & ELISA & $37.6(32.1-43.1)$ & $67.1(61.7-72.5)$ & 73.8 (68.8-78.8) & {$[6]$} \\
\hline Guangdong & ELISA & $7.7(6.2-9.2)$ & $3.2(2.2-4.2)$ & $10.9(9.1-12.7)$ & {$[11]$} \\
\hline Shanghai & ELISA & $29.2(23.2-35.3)$ & na & $29.2(23.2-35.3)$ & {$[12]$} \\
\hline Shanxi & ELISA & $1.0(0.0-2.5)$ & $44.3(37.2-51.4)$ & $44.3(37.2-51.4)$ & {$[6]$} \\
\hline Hebei & ELISA & $30.2(17.4-43.0)$ & $28.3(15.8-40.8)$ & 54.7 (40.9-68.6) & {$[6]$} \\
\hline Jiangsu & ELISA & $4.0(1.4-6.5)$ & $35.2(29.0-41.5)$ & $37.4(31.1-43.8)$ & {$[6]$} \\
\hline Beijing & ELISA & $2.0(0.0-4.3)$ & $34.2(26.5-41.9)$ & $34.9(27.2-42.6)$ & {$[6]$} \\
\hline Guizhou & PCR & $74.0(66.1-81.8)$ & $11.4(5.7-17.1)$ & $74.0(66.1-81.8)$ & {$[7]$} \\
\hline Ningxia & ELISA & $4.0(1.3-6.7)$ & $77.6(71.8-83.4)$ & $80.1(74.5-85.7)$ & {$[6]$} \\
\hline Gansu & PCR & $28.1(22.4-33.8)$ & $2.9(0.8-5.0)$ & $31.0(25.1-36.9)$ & [13] \\
\hline
\end{tabular}

Abbreviation: na, not available 


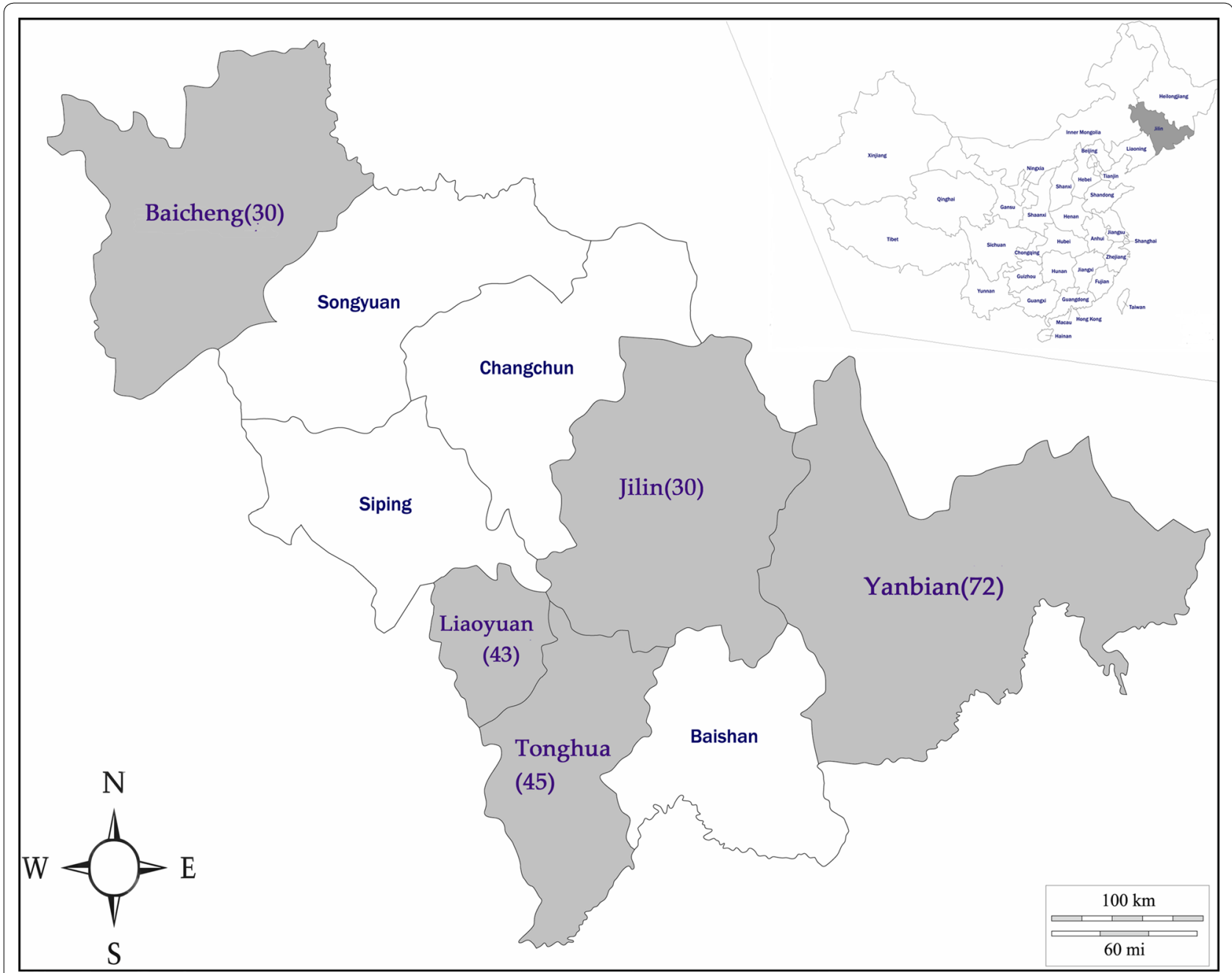

Fig. 1 Map of the sampling districts in Jilin, China. The number within each region represents the sample size collected in this study

a template for conventional PCR and nested PCR (nPCR) amplification based on previously published procedures using T. equi-specific primers to target the $18 S$ rRNA gene [14] and the B. caballi-specific BC48 gene [15]. The PCR reaction was conducted in a $25 \mu$ l reaction mixture comprised of $1 \mu \mathrm{l}$ of each primer (10 pmol), $3 \mu \mathrm{l}$ template DNA (45-55 ng/ $\mu \mathrm{l}), 2 \mu \mathrm{l}$ dNTP mix (TaKaRa, Dalian, China), $2.5 \mu \mathrm{l}$ of $10 \times$ Ex Taq buffer, $0.25 \mu \mathrm{l}$ Ex Taq $(\mathrm{TaKaRa})$, and $15.25 \mu \mathrm{l}$ distilled water. Genomic DNA extracted from the blood of horses naturally infected with T. equi and B. caballi was used as a positive control. Distilled water was used as a negative control. The nucleotide sequences of the primers and procedures of the PCR cycling conditions are presented in Table 2.

\section{Sequencing and phylogenetic analysis}

Amplicons from positive PCR products were purified using a Gel Extraction Kit (OMEGA, Norcross, GA,
USA) and were then cloned into a PMD 18T-Simple Vector (TaKaRa). The recombined clone plasmids were transformed into competent DH5 $\alpha$ cells (TaKaRa). Following transformation, the precisely identified amplicons were sequenced by Shanghai Yingweijieji Biotechnology Company.

The obtained sequences were initially analyzed using the BLASTn program on the NCBI website. All sequences obtained in this study were aligned using ClustalW and then manually edited using Bioedit v.7.0.9 software (Fig. 2) [16]. Phylogenetic trees were constructed using the maximum likelihood (ML) (MEGA v.7.0) and Bayesian (MrBayes 3.2) methods [17]. For the ML analysis, a Tamura-3-parameter model and bootstrapping of 1000 replicates were selected to calculate the evolutionary relationship using MEGA v.7.0 software. The Bayesian analysis was performed using MrBayes 3.2 
Table 2 Primer sequences for the amplification of T. equi and/or B. caballi

\begin{tabular}{|c|c|c|c|c|c|c|c|}
\hline Organism-s & Target gene & Assay & Product size (bp) & Primer & Sequence $5^{\prime}-3^{\prime}$ & $\begin{array}{l}\text { Annealing } \\
\text { temperature } \\
\left({ }^{\circ} \mathrm{C}\right)\end{array}$ & Reference \\
\hline \multirow[t]{2}{*}{ T. equi } & 18S rRNA & PCR & 435 & P1 & TCGAAGACGATCAGATACCGTCG & 60 & [14] \\
\hline & & & & P2 & TGCCTTAAACTTCCTTGCGAT & & \\
\hline \multirow[t]{4}{*}{ B. caballi } & BC48 & Nested PCR & 454 & P3 & ACGAATTCCCACAACAGCCGTGTT & 55 & [15] \\
\hline & & & & P4 & ACGAATTCGTAAAGCGTGGCCATG & & \\
\hline & & & & P5 & GGGCGACGTGACTAAGACCTTATT & & \\
\hline & & & & P6 & GTTCTCAATGTCAGTAGCATCCGC & & \\
\hline \multirow[t]{4}{*}{ T. equi/B. caballi } & $18 \mathrm{~S}$ rRNA & Nested PCR & $\sim 1400$ & P7 & GAAAYTGCGAATGGCTCATTAM & 57 & [13] \\
\hline & & & & P8 & CACCGGATCACTCGATCGGTAGG & & \\
\hline & & & & P9 & GGATAACCGTGSTAATTSTAGGGC & & \\
\hline & & & & P10 & GTGTGTACAAAGGGCAGGGACG & & \\
\hline
\end{tabular}

software. We ran four Monte Carlo Markov chains for $10^{6}$ generations, sampling every $10^{3}$ generations with the GTR + G + I model. The initial 25\% samples were discarded as 'burn-in'.

\section{Statistical analysis}

The epidemiological data generated in this study were analyzed to identify which variables were associated with the equine piroplasm infection. A Fisher's exact or chisquare test was performed to assess the significant differences among the regions, management, sex, and species based on the prevalence of T. equi and/or B. caballi. Variables yielding a significant association ( $P$-value $\leq 0.05$, two-tailed) were further applied in a stepwise backward logistic regression analysis [18]. Variance inflation factor (VIF) was calculated to test and avoid multicollinearity among variables. The fitness of the final models was assessed using a Hosmer-Lemeshow test, Negelkerke $R^{2}$ test, and the observed versus predicted values (residual statistics) [19]. The 95\% confidence intervals (95\% CI), odds ratios (OR), and $P$-values were also computed. Differences were considered to be statistically significant if $P<0.05$. All analyses were performed using SPSS software version 19.0 (IBM SPSS Statistics for Windows, Version 19.0. Armonk, IBM Corp., NY, USA) [20].

\section{Results}

Molecular detection of equine piroplasm

The PCR amplification results showed that the T. equi PCR amplified fragments of $435 \mathrm{bp}$ (P1 and P2) from 61 samples had a positive rate of $22.7 \%(61 / 220)$. All of the surveyed samples were negative for B. caballi (P3P6). Among the five regions studied, the highest prevalence of $T$. equi was recorded in Baicheng (43.3\%, 95\% CI: $24.5-62.2 \%)$, whereas the lowest prevalence was observed in Liaoyuan (20.9\%, 95\% CI: 8.3-33.6\%). The prevalence among these two regions differed significantly $(P<0.05)$. The infection rates were detected in the other three regions of Tonghua (28.9\%, 95\% CI: 15.1-42.7\%), Yanbian (26.4\%, 95\% CI: $16.0-36.8 \%)$, and Jilin (23.3\%, 95\% CI: 7.3-39.4\%) (Table 3). The molecular prevalence of T. equi was also analyzed in the different categories of equids based on management, sex and species. The equids from the organized farms had a significantly lower positive rate $(18.3 \%)$ compared to those from the unorganized farms $(34.6 \%)(P<0.05)$. The prevalence between the different sexes showed that the female equid population $(32.1 \%)$ was more prone to infection compared with the males $(16.1 \%)(P<0.05)$. In this study, 192 horses and 28 donkeys/mules were compared for the prevalence of T. equi. The former had a higher prevalence $(28.1 \%, 95 \%$ CI: $21.7-34.5 \%)$ than the latter group (25\%, 95\% CI: $7.9-$ 42.1\%) (Table 3).

The results of VIF analysis $(\mathrm{VIF}<1.2)$ showed that there was no multicollinearity among all variables. In the first step of the risk factor analysis, four variables (region, farm management, equine species and sex) were assessed using a bivariate analysis. The results of the analysis in the univariate model indicated that two variables (management and sex) were sufficiently significant $(P<0.05)$ for further analysis. The region was also collected as a potential risk factor to be included in the multivariable analysis. A Hosmer-Lemeshow test $\left(\chi^{2}=6.18, d f=4\right.$, $P=0.186)$ and Nagelkerke $R^{2}(0.120)$ values suggested that this model was a good fit. The results of the multivariate logistic analysis suggested that females, equines of Baicheng, or unorganized farms were more likely to test positive for T. equi (Table 4).

\section{Sequencing analysis}

A total of 61 T. equi $18 S$ rRNA gene sequences (approximately $1400 \mathrm{bp}$ ) were successfully obtained from the 


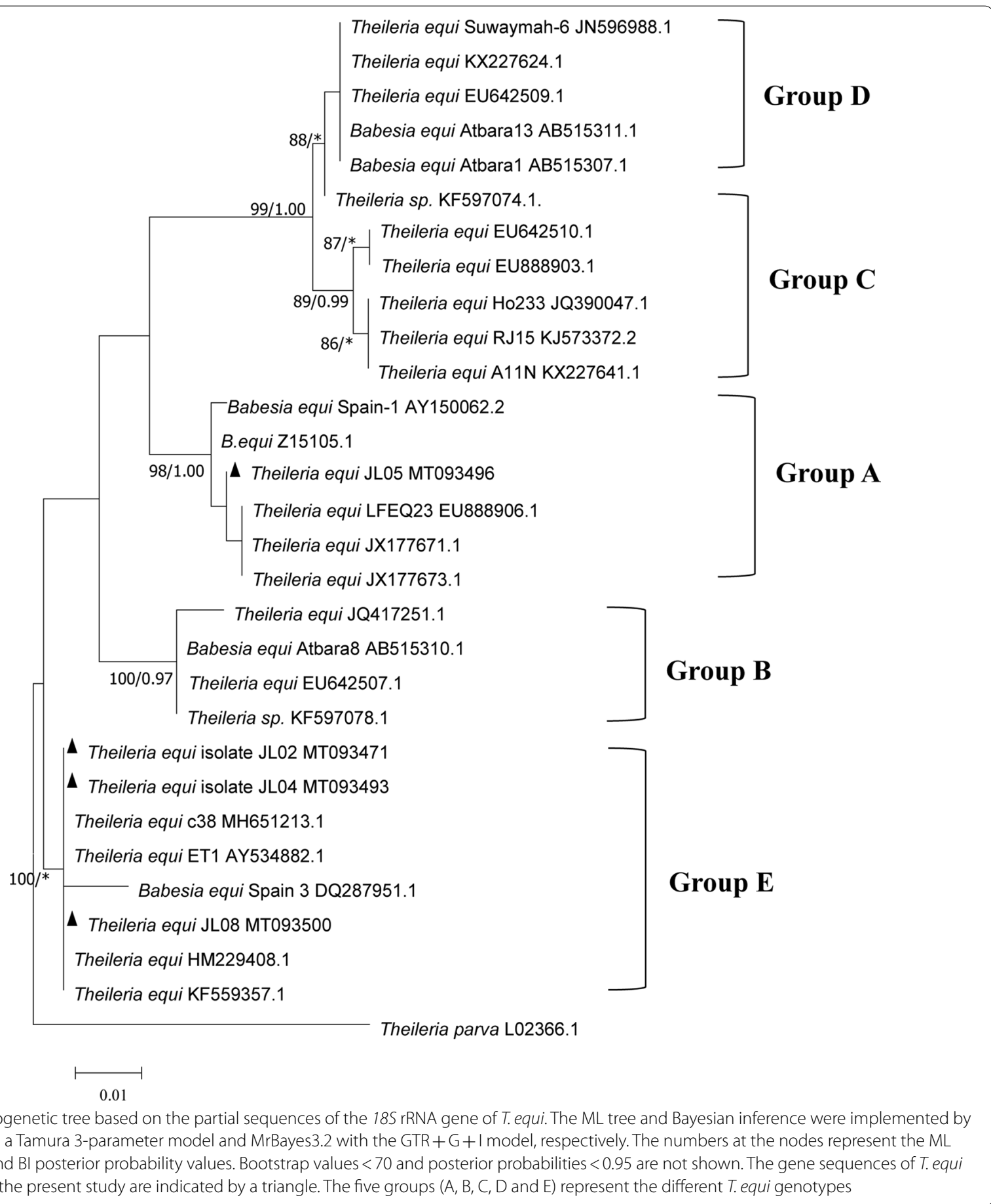

previous identified positive samples by nPCR, which further confirmed the results (435 bp) obtained from the PCR diagnosis. The BLAST analysis revealed four different haplotypes of the $18 \mathrm{~S}$ rRNA gene sequences in this study. Therefore, four $18 \mathrm{~S}$ rRNA sequences (MT093471, MT093493, MT093496 and MT093500) were deposited in the GenBank database. The new T. equi $18 \mathrm{~S}$ rRNA gene sequences obtained in this study showed 96.899.9\% sequence identity to each another. All new isolates, except for JL05 (GenBank: MT093496), which displayed the highest sequence identity (99.2\%) with Chile (GenBank: MT463613) and had the highest sequence identities with the strains isolated from South Korea (GenBank: HM229407), varying from $99.8-100 \%$. 
Table 3 Results of the univariate analyses for the prevalence of T. equi

\begin{tabular}{|c|c|c|c|c|c|c|}
\hline Variable & $\begin{array}{l}\text { Samples tested (positive/total } \\
\text { samples tested) }\end{array}$ & Prevalence (\%) & $95 \% \mathrm{Cl}$ & OR & $95 \% \mathrm{Cl}$ & $P$-value \\
\hline \multicolumn{7}{|l|}{ Region } \\
\hline Liaoyuan & $9 / 43$ & 20.9 & $8.3-33.6$ & Ref & & \\
\hline Baicheng & $13 / 30$ & 43.3 & $24.5-62.2$ & 2.89 & $1.03-8.09$ & $0.04^{*}$ \\
\hline Jilin & $7 / 30$ & 23.3 & $7.3-39.4$ & 1.15 & $0.38-3.53$ & 0.80 \\
\hline Yanbian & $19 / 72$ & 26.4 & $16.0-36.8$ & 1.35 & $0.55-3.34$ & 0.51 \\
\hline Tonghua & $13 / 45$ & 28.9 & $15.1-42.7$ & 1.54 & $0.58-4.08$ & 0.39 \\
\hline \multicolumn{7}{|l|}{ Management } \\
\hline Unorganized & $44 / 127$ & 34.6 & $26.3-43.0$ & Ref & & \\
\hline Organized & $17 / 93$ & 18.3 & $10.3-26.3$ & 0.42 & $0.22-0.80$ & $0.007^{* *}$ \\
\hline \multicolumn{7}{|l|}{ Sex } \\
\hline Male & $10 / 62$ & 16.1 & $6.7-25.5$ & Ref & & \\
\hline Female & $51 / 158$ & 32.3 & 24.9-39.6 & 2.48 & $1.17-5.27$ & $0.016^{*}$ \\
\hline \multicolumn{7}{|l|}{ Species } \\
\hline Horse & $54 / 192$ & 28.1 & $21.7-34.5$ & Ref & & \\
\hline Donkey/mule & $7 / 28$ & 25.0 & $7.9-42.1$ & 0.85 & $0.34-2.12$ & 0.73 \\
\hline Total & $61 / 220$ & 27.7 & $21.8-33.7$ & & & \\
\hline
\end{tabular}

Abbreviations: Ref, reference; $95 \% \mathrm{Cl}$, confidence interval

${ }^{*} P<0.05$, ${ }^{*} P<0.01$

Table 4 Results of the multivariate logistic analysis of risk factors for predicting T. equi infection in Jilin, China

\begin{tabular}{lllll}
\hline Variable & Category & P-value & Odds ratio & $95 \% \mathrm{Cl}$ \\
\hline Region & All other regions & $\mathrm{a}$ & & \\
& Baicheng & 0.006 & 3.452 & $1.414-8.424$ \\
Management & Unorganized & $\mathrm{a}$ & & \\
& Organized & 0.020 & 0.456 & $0.235-0.886$ \\
Sex & Male & $\mathrm{a}$ & & \\
& Female & 0.012 & 2.924 & $1.269-6.737$ \\
\hline
\end{tabular}

Abbreviations: a, baseline; $95 \% \mathrm{Cl}$, confidence interval

\section{Phylogenetic analysis}

The T. equi phylogenetic tree was constructed using the $18 S$ rRNA gene sequences obtained in our study and those previously published in GenBank. The tree topologies generated with the ML and BI analyses were generally similar. Therefore, the topology of the ML tree was presented with the support values $(\mathrm{ML} / \mathrm{BI})$ indicated on the branches. Phylogenetic analyses based on the T. equi $18 S$ rRNA gene sequences in this study showed evidence of five main groups, which represent five genotypes, termed A, B, C, D and E [21] (Fig. 2). The results of the phylogenetic analysis indicated that the T. equi $18 \mathrm{~S}$ rRNA gene sequences from Jilin Province obtained in the present study belonged to genotypes $\mathrm{A}$ and $\mathrm{E}$. The new sequences of T. equi genotype E (MT093471, MT093493 and MT093500) obtained in this study shared 99.2-99.5\% identities with a reference sequence from Spain (GenBank: DQ287951). Within group A, the T. equi $18 S$ rRNA gene (GenBank: MT093496) sequence formed one clade with South Africa (GenBank: EU888906) and shared a $99.2 \%$ nucleotide identity. In addition, the two T. equi genotype groups, $\mathrm{C}$ and $\mathrm{D}$, had a closer kinship, which was supported by the results of the statistical analysis (99\% ML/1.00 BI).

\section{Discussion}

The GenBank database of the National Center for Biotechnology Information (NCBI), contains published sequences of endemic T. equi and B. caballi isolates from more than 35 countries. The prevalence of EP occurs most frequently in the spring and autumn and is closely related to tick vector activity. Jilin Province is located within the middle of northeast China, which is rich in forest resources and animal species. This superior ecological environment provides a greater benefit to humans and is also a breeding ground for ticks. In this study, we found that the overall molecular prevalence of $T$. equi was $27.7 \%$, which is significantly lower than the previous results (43.3\%) detected by Xiong et al. [22]. This high degree of variability in the prevalence rates should be interpreted with extreme caution, due to differences in the sampling areas, sample size, animal species, and control programmes [23, 24]. However, infection with B. caballi was not identified in the present study, which could be attributed to the absence of competent tick 
vectors in the sampling areas, time and range. The existence of competent tick vectors is critical for maintaining the life-cycles of these parasites. There were 15 and 14 separate species of ticks reported as competent vectors for the transmission of B. caballi and T. equi, respectively [1]. However, the tick material collected from equines was absent and further studies must be implemented to confirm the competent tick vector responsible for the spread of EP in Jilin. Furthermore, equids infected with $B$. caballi are typically capable of naturally eliminating the infection, and imidocarb treatment has a reliably good curative effect at the recommended dosage for these parasites [25]. In contrast, once infected with T. equi, equids remain carriers throughout their lifetime and represent important reservoirs of this protozoan for naïve tick vectors [26, 27]. Due to the limitations associated with the sample size and narrow age range, most of the samples collected in this study were aged four to eight years of age. Therefore, there remains a need to establish the prevalence of B. caballi in Jilin.

In this study, we evaluated the risk factors considered to be associated with T. equi infection. It was observed that the samples collected from Baicheng had the highest positive rate $(43.3 \%)$ compared to other areas. Baicheng is located in the northwest region of Jilin Province, which neighbors the grassland of Inner Mongolia and is characterized by abundant vegetation resources that provides a suitable environment for tick reproduction. This may be a crucial factor for greater infection of T. equi among equids in Baicheng; however, no significant differences were found among all other regions. The prevalence of $T$. equi infection in the organized farms (18.3\%) was significantly lower than that detected in the unorganized farms (34.6\%). Animals fed in an organized farm may have good management practices (e.g. deworming, vaccination, and veterinary care), which can effectively reduce the incidence of $T$. equi infection. However, animals within an unorganized farm are consistently fed by grazing or with other domestic animals, which may increase the risk of $T$. equi infection $[28,29]$. The positive rate was significantly higher $(32.3 \%)$ in the female population compared with the males (16.1\%), which is consistent with the findings of other studies $[18,30]$. This discrepancy in the prevalence of different sexes can be explained by the fact that the majority of the males sampled from farms in this study were stallions, which have greater value for breeding. In general, equines destined for reproductive activity (e.g. stallions) receive management considered to be ideal for this type of breeding via appropriate zootechnical buildings. Under such conditions, the animals receive balanced meals, systematic veterinary care, and sanitary control; thus, they are at a decreased risk of infestation with a tick vector and other reservoir hosts [31]. The relationship between sex hormones and susceptibility of males and females to protozoan infections has been studied in multiple species [32]. However, whether similar effects exist for equine piroplasm infection may require further research. The prevalence of T. equi infection was higher $(28.1 \%)$ in the horse population as compared with donkeys/mules (25.0\%), which differs from previous studies conducted in India and Italy [33,34]. In these previous studies, the donkeys/mules possessed higher positive rates than the horses, because donkeys/mules are primarily used as working equids and are generally reared in poor living conditions, which may increase the chances of contact with infected tick vectors and other ruminants. This discrepancy in the prevalence within different regions may be attributed to differences in the purpose of husbandry. In this study, donkeys/mules are primarily raised for the purpose of food sources and leisure activities, which require stricter livelihood conditions and parasitic control programmes. Horses used for exhibition and sports typically have a higher prevalence of $T$. equi infection [31], and similar results were observed in this study.

Based on the analysis of the $18 S$ rRNA gene variants, we found two T. equi $18 \mathrm{~S}$ rRNA genotypes, which were designated as genotypes $\mathrm{A}$ and $\mathrm{E}$. Within group E, T. equi genotype $E$ has recently been reported in Gansu (GenBank: MH651213), which shares $99.9-100 \%$ similarity with the isolates (MT093471, MT093493 and MT093500) obtained in our study [13]. The pairwise comparison indicated that there were no more than two nucleotide differences in both Theileria sequences, which confirmed that T. equi genotype E presented in these two areas should be considered a variation of the same strain. The severe pathogenicity associated with $T$. equi genotype $\mathrm{E}$ may be closely related to the clinical death of horses, which has been reported in both Spain and Greece [35, 36]. The results of our study indicate that the T. equi genotype $\mathrm{E}$ is widespread in Jilin Province. Although most of the cases in this study appeared to be asymptomatic, the prevalence of this genotype requires further research. Furthermore, one sequence belonging to $T$. equi genotype A that was first reported in South Africa (GenBank: Z15105) was identified in our study and has seldom been reported in China. Further information of the T. equi genotype A is needed to evaluate the association between this genotype with the prevalence of EP.

The occurrence of equine piroplasmosis has been reported in several regions of China, which has caused considerable economic loss to the equine industry. To understand the prevalence of EP over time, specimens were collected from five counties in Jilin Province to investigate the infection rate and analyze the epidemiology of EP. The findings of our study provided scientific evidence regarding 
the prevalence and geographical distribution of EP in Jilin, China, which is beneficial for controlling the source of infection, cut-off transmission routes, and to further protect susceptible equids.

\section{Conclusions}

To our knowledge, this is the first study to investigate the genetic diversity of $T$. equi in equids from Jilin Province, China. The results of the present study revealed that the region was endemic for equine piroplasmosis with $T$. equi enzootic stability. Only the risk factors of sex and farm management were associated with $T$. equi infection in equids of the northeastern region in China. These factors should be used for the development or improvement of programmes for the prevention and control of equine piroplasmosis in the studied region.

\section{Abbreviations}

EP: equine piroplasmosis; PCR: polymerase chain reaction; $\mathrm{nPCR}$ : nested PCR; $18 S$ rRNA: 18 Svedberg ribosomal ribonucleic acid.

\section{Acknowledgements}

Not applicable.

\section{Authors' contributions}

SWZ and LJ conceived and designed the experiments. SWZ, HW and SZ performed the experiments. SZX, HL and XCZ contributed reagents and materials. SWZ and LJJ wrote the manuscript. All authors read and approved the final manuscript.

\section{Funding}

This study was supported by the Scientific Research and Innovation Team Project of Yanbian University, the Talent Fund Funded Talent Project of Jilin Province (project no. [2019] 874), the Leading Talents and Teams of Young and Middle-aged Technological Innovation in Jilin Province (20200301034RQ) and supported by the 111 Project (D20034)

\section{Availability of data and materials}

All data supporting the conclusions of this article are included within the article. The newly generated sequences were deposited in the GenBank database under the accession numbers MT093471, MT093493, MT093496 and MT093500.

\section{Ethics approval and consent to participate}

Collection of the samples was carried out with permission by the farm owners, and equids involved in sampling were well looked after. All experimental procedures in animals were conducted following the Ethical Principles in Animal Research issued by Yanbian University.

\section{Consent for publication}

Not applicable.

\section{Competing interests}

The authors declare that they have no competing interests.

Received: 9 May 2020 Accepted: 1 September 2020

Published online: 09 September 2020

\section{References}

1. Wise LN, Kappmeyer LS, Mealey RH, Knowles DP. Review of equine piroplasmosis. J Vet Intern Med. 2013:27:1334-46.
2. Jongejan F, Uilenberg G. The global importance of ticks. Parasitology. 2004;129:S3-14.

3. Kappmeyer LS, Thiagarajan M, Herndon DR, Ramsay JD, Caler E, Djikeng A, et al. Comparative genomic analysis and phylogenetic position of Theileria equi. BMC Genomics. 2012;13:603.

4. Schein FB, Maia MO, Witter R, Marcili A, Camargo LM, Dutra V, et al. Molecular survey and genetic diversity of piroplasmids in equids from Midwestern Brazil. Rev Bras Parasitol Vet. 2018;27:464-72.

5. Hou HB, Li HJ, Zhang L. Research advences on functional genes of main economic traits in horses and donkeys. Chin An Husb Vet Med. 2018:45:2670-80.

6. Wang M, Guo W, Igarashi I, Xuan X, Wang X, Xiang W, et al. Epidemiological investigation of equine piroplasmosis in China by enzyme-linked immunosorbent assays. J Vet Med Sci. 2014;76:549-52.

7. Xue Y. Serological and pathogenic study of the major infectious diseases in Guizhou pony. Ph.D. Thesis, Guizhou University, Guiyang; 2016.

8. Zhang Y, Chahan B, Liu S, Song R, Li Y, Huercha. Epidemiologic studies on Theileria equi infections for grazing horses in Ili of Xinjiang province. Vet Parasitol. 2017;244:111-3.

9. Battsetseg B, Lucero S, Xuan X, Claveria FG, Inoue N, Alhassan A, et al. Detection of natural infection of Boophilus microplus with Babesia equi and Babesia caballi in Brazilian horses using nested polymerase chain reaction. Vet Parasitol. 2002;107:351-7.

10. Alhassan A, Pumidonming W, Okamura M, Hirata H, Battsetseg B, Fujisaki $\mathrm{K}$, et al. Development of a single-round and multiplex PCR method for the simultaneous detection of Babesia caballi and Babesia equi in horse blood. Vet Parasitol. 2005;129:43-9.

11. Huang $Y H, H e G Q$, Peng DP, Li WY, Zhang XP. Serological investigation for equine piroplasmosis in region of Dongwan, Guangdong. Heilongjiang Anim Sci Vet Med. 2016;8:146-7.

12. Ning K, Li KH, Yang XC, Wang J. Seroprevalence of equine piroplasmosis and trypanosomiasis in horses in Shanghai. Shanghai J Anim Husb Vet Med. 2014;5:38-9.

13. Wang J, Liu J, Yang J, Wang X, Li Z, Jianlin X, et al. The first molecular detection and genetic diversity of Babesia caballi and Theileria equi in horses of Gansu province, China. Ticks Tick Borne Dis. 2019;10:528-32.

14. Xiong HZ, Liu B, Zhang SF. Establishment and application of the PCR method for detection of Babesia equi. Agric Sci J Yanbian Univ. 2007;29:129-33.

15. Battsetseg B, Xuan X, Ikadai H, Bautista JLR, Fujisaki K. Detection of Babesia caballi and Babesia equi in Dermacentor nuttalli adult ticks. Int J Parasitol. 2001;31:384-6.

16. Thompson JD, Higgins DG, Gibson TJ. CLUSTAL W: improving the sensitivity of progressive multiple sequence alignment through sequence weighting, position-specific gap penalties and weight matrix choice. Nucleic Acids Res. 1994;22:4673-80.

17. Sun Z, Jiang C, Feng J, Yang W, Li M, Miao W. Phylogenomic analysis of Balantidium ctenopharyngodoni (Ciliophora, Litostomatea) based on single-cell transcriptome sequencing. Parasite. 2017;24:43.

18. Bartolomé Del Pino LE, Nardini R, Veneziano V, lacoponi F, Cersini A, Autorino GL, et al. Babesia caballi and Theileria equi infections in horses in central-southern Italy: Sero-molecular survey and associated risk factors. Ticks Tick Borne Dis. 2016:7:462-9.

19. Urdaz-Rodríguez JH, Fosgate GT, Alleman AR, Rae DO, Donovan GA, Melendez P. Seroprevalence estimation and management factors associated with high herd seropositivity for Anaplasma marginale in commercial dairy farms of Puerto Rico. Trop Anim Health Prod. 2009;41:1439-48.

20. Dahiya R, Salar RK, Mandal KD, Kumar R, Tripathi BN, Pal Y, et al. Risk factor analysis associated with Theileria equi infected equines in semi-arid and sub-humid ecological enzootic zones of India. Vet Parasitol Reg Stud Rep. 2018;12:17-21

21. Liu Q, Meli ML, Zhang Y, Meili T, Stirn M, Riond B, et al. Sequence heterogeneity in the 18S rRNA gene in Theileria equi from horses presented in Switzerland. Vet Parasitol. 2016:221:24-9.

22. Xiong HZ, Zhang SF, Liu B. An investigation of Babesia equi in horses in Jilin Province. Chin J Vet Med. 2009;45:40-1.

23. García-Bocanegra I, Arenas-Montes A, Hernández E, Adaszek L, Arenas A. Seroprevalence and risk factors associated with Babesia caballi and Theileria equi infection in equids. Vet J. 2012;195:172-8. 
24. Qablan MA, Obornik M, Petrzelkova KJ, Sloboda M, Shudiefat MF, Horin P, et al. Infections by Babesia caballi and Theileria equi in Jordanian equids: epidemiology and genetic diversity. Parasitology. 2013;140:1096-103.

25. Hussain MH, Saqib M, Raza F, Muhammad G, Asi MN, Mansoor MK, et al. Seroprevalence of Babesia caballi and Theileria equi in five draught equine populated metropolises of Punjab, Pakistan. Vet Parasitol. 2014;202:248-56.

26. de Waal DT. Equine piroplasmosis: a review. Br Vet J. 1992;148:6-14.

27. Ueti MW, Palmer GH, Scoles GA, Kappmeyer LS, Knowles DP. Persistently infected horses are reservoirs for intrastadial tick-borne transmission of the apicomplexan parasite Babesia equi. Infect Immun. 2008;76:3525-9.

28. Heuchert CM, de Giulli V Jr., Athaide DF, Bose R, Friedhoff KT. Seroepidemiologic studies on Babesia equi and Babesia caballi infections in Brazil. Vet Parasitol. 1999;85:1-11.

29. Abutarbush SM, Alqawasmeh DM, Mukbel RM, Al-Majali AM. Equine babesiosis: seroprevalence, risk factors and comparison of different diagnostic methods in Jordan. Transbound Emerg Dis. 2012;59:72-8.

30. Sumbria D, Singla LD, Sharma A, Bal MS, Randhawa CS. Molecular survey in relation to risk factors and haemato-biochemical alteration in Theileria equi infection of equines in Punjab Province, India. Vet Parasitol Reg Stud Reports. 2017;8:43-50.
31. Dos Santos TM, Roier EC, Santos HA, Pires MS, Vilela JA, Moraes LM, et al. Factors associated to Theileria equi in equids of two microregions from Rio de Janeiro, Brazil. Rev Bras Parasitol Vet. 2011;20:235-41.

32. Roberts CW, Walker W, Alexander J. Sex-associated hormones and immunity to protozoan parasites. Clin Microbiol Rev. 2001;14:476-88.

33. Sumbria D, Singla LD, Kaur P. Sero-prevalence and risk factor analysis of Theileria equi infection in equids from different agro-climatic zones of Punjab (India) by indirect immunofluorescence antibody test. Vet Parasitol Reg Stud Rep. 2018;13:18-20.

34. Piantedosi D, D'Alessio N, Di Loria A, Di Prisco F, Mariani U, Neola B, et al. Seroprevalence and risk factors associated with Babesia caballi and Theileria equi infections in donkeys from Southern Italy. Vet J. 2014;202:578-82.

35. Kouam MK, Kantzoura V, Masuoka PM, Gajadhar AA, Theodoropoulos G. Genetic diversity of equine piroplasms in Greece with a note on speciation within Theileria genotypes (T. equi and T. equi-like). Infect Genet Evol. 2010;10:963-8.

36. Nagore D, García-Sanmartín J, García-Pérez AL, Juste RA, Hurtado A. Detection and identification of equine Theileria and Babesia species by reverse line blotting: epidemiological survey and phylogenetic analysis. Vet Parasitol. 2004;123:41-54

\section{Publisher's Note}

Springer Nature remains neutral with regard to jurisdictional claims in published maps and institutional affiliations.
Ready to submit your research? Choose BMC and benefit from:

- fast, convenient online submission

- thorough peer review by experienced researchers in your field

- rapid publication on acceptance

- support for research data, including large and complex data types

- gold Open Access which fosters wider collaboration and increased citations

- maximum visibility for your research: over $100 \mathrm{M}$ website views per year

At BMC, research is always in progress.

Learn more biomedcentral.com/submissions 